\title{
Investigation of liquid phase axial dispersion in Taylor bubble flow by radiotracer residence time distribution analysis
}

\author{
I.R. Chughtai ${ }^{1}$, W. Iqbal ${ }^{1}$, G.U. Din ${ }^{2}$, S. Mehdi ${ }^{1}$, I.H. Khan ${ }^{2}$, M.H. Inayat ${ }^{1}$ and J.H. Jin ${ }^{3}$ \\ ${ }^{1}$ Department of Chemical Engineering, Pakistan Institute of Engineering and Applied Sciences [PIEAS], P.O \\ Nilore, Islamabad, Pakistan \\ ${ }^{2}$ Isotope Applications Division, Pakistan Institute of Nuclear Science and Technology [PINSTECH], P.O Nilore, \\ Islamabad, Pakistan \\ ${ }^{3}$ Division of Physical and Chemical Sciences, Department of Nuclear Sciences and Applications, International \\ Atomic Energy Agency [IAEA], Vienna, Austria
}

\begin{abstract}
A gas-liquid Taylor bubble flow occurs in small diameter channels in which gas bubbles are separated by slugs of pure liquid. This type of flow regime is well suited for solid catalyzed gas-liquid reactors in which the reaction efficiency is a strong function of axial dispersion in the regions of pure liquid. This paper presents an experimental study of liquid phase axial dispersion in a Taylor bubble flow developed in a horizontal tube using high speed photography and radiotracer residence time distribution (RTD) analysis. A parametric dependence of axial dispersion on average volume fraction of gas phase was also investigated by varying the relative volumetric flow rates of the two phases. ${ }^{137 \mathrm{~m}} \mathrm{Ba}$ produced from a ${ }^{137} \mathrm{Cs} /{ }^{137 \mathrm{~m}} \mathrm{Ba}$ radionuclide generator was used as radiotracer and measurements were made using the $\mathrm{NaI}(\mathrm{Tl})$ scintillation detectors. Validation of ${ }^{137 \mathrm{~m}} \mathrm{Ba}$ in the form of barium chloride as aqueous phase radiotracer was also carried out. Axial Dispersion Model (ADM) was used to simulate the hydrodynamics of the system and the results of the experiment are presented. It was observed that the system is characterized by very high values of Peclet Number $\left(\mathrm{Pe} \sim 10^{2}\right)$ which reveals an approaching plug type flow. The experimental and model estimated values of mean residence times were observed in agreement with each other.
\end{abstract}

\section{INTRODUCTION}

The two-phase gas-liquid flow in tubes is very important in process engineering operations. The flow patterns in such tubular flows are vital considerations for transport phenomena. These flow patterns depend on the geometrical and operating parameters and on the properties of the flowing fluids. If the gas is dispersed as very small bubbles in the liquid phase, the flow is called as bubble flow. If the gas moves in the form of large bubbles separated by liquid slugs which also contains small gas bubbles, the flow is attributed as slug flow. The flow pattern in a tube characterized by bubbles separated from one another by liquid phase slugs, and from the channel walls by a thin liquid film with no gas entrained is referred as the Taylor bubble flow. This kind of flow systems are of great importance in two phase flow in several applications, such as two phase flow through porous media, boiling in tubes, analytical devices and monolithic catalytic reactors. In monolithic reactors, the catalyst consists of a large number of straight porous channels in which the liquid and gas flow co-currently. Previous studies [1] have shown that the slug flow and Taylor bubble flow gives the best mass transfer properties in the monolith channels. In this flow pattern, Taylor bubbles give rise to a re-circulation within the liquid slugs by avoiding the development of parabolic flow in liquid slugs. This re-circulation enhances the radial mass transfer between the phases involved but axial dispersion in the regions of pure liquid flow may affect the process efficiency and thus needs special care.

Previous studies have focused on the measurement of axial dispersion in Taylor bubble flow systems using conventional methods including colourimetry, spectrophotometer and optical detectors [2-5]. These experimental approaches present some disadvantages including low sensitivity and poor statistics. Most important of all is that one needs to shut down the operation to obtain holdup fraction at each operating parameter.

Radiotracer technology offers state of the art technique for industrial process optimization and trouble shooting due to high sensitivity, on-line measurement, better statistics and high benefit to cost ratio. The unique ability of this technology is that it can provide information that may not be obtained by other techniques. This technology has been widely used in developed countries to help solve industrial problems [6-9]. It is also flourishing in developing countries [10-15] but facing a major constraint due to the unavailability of radiotracers at the time of requirement. For countries that do not possess radioisotope production facilities, it is necessary to import the radiotracers and long time involved in this process rules out the possibility of achieving potential benefit of this technology. Medical radionuclide generators such as ${ }^{99} \mathrm{Mo} /{ }^{99 \mathrm{~m}} \mathrm{Tc}$ and ${ }^{113} \mathrm{Sn} /{ }^{113 \mathrm{~m}} \mathrm{In}$ provide a partial solution to the problem but radiotracers from these generators have limited applications in industry because of their low gamma energies and adsorption on solid surfaces depending on the chemical and physical conditions. Hence, there is a need to explore some more nuclear genetic relationships that may form the basis for the development of radionuclide generators for industrial process investigations. Keeping in view of these considerations, a novel industrial radionuclide generator (IRG) system $\left({ }^{137} \mathrm{Cs} /{ }^{137 m} \mathrm{Ba}\right.$ ) has been developed especially for industrial process 


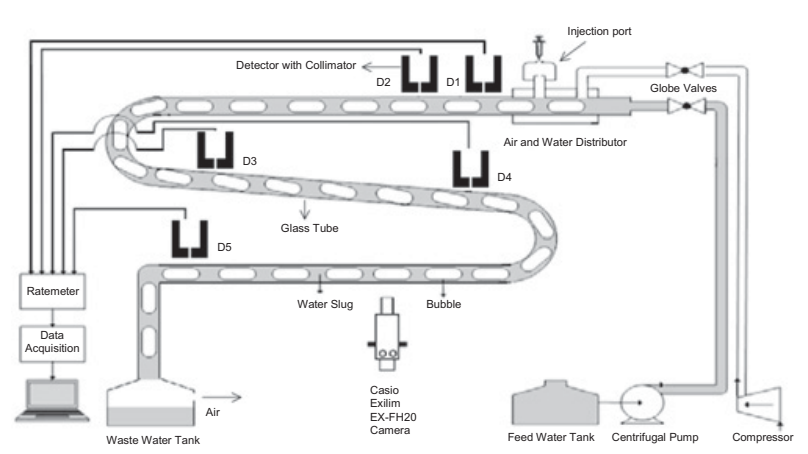

Figure 1. Schematic diagram of a Taylor bubble flow setup under investigation.

investigations [16]. This IRG system produces ${ }^{137 m} \mathrm{Ba}$ radiotracer in the form of barium chloride with gamma energy $0.662 \mathrm{MeV}$. A major attraction of this IRG lies in the half-lives of mother (30.17 years) and daughter (2.55 minutes). Due to high gamma energy of the daughter, the radiotracer produced from this radionuclide generator is useful in industrial systems having thick metallic walls. Moreover, the short half-life of daughter ensures quick decontamination of the systems under investigation.

The present study is focused to study the liquid phase axial dispersion in a Taylor bubble flow developed in a horizontal tube using high speed photography and radiotracer residence time distribution (RTD) analysis. A parametric dependence of axial dispersion on average volume fraction of gas phase was also investigated by varying the relative volumetric flow rates of the two phases.

\section{MATERIALS AND METHODS}

A simplified two-phase Taylor bubble flow experimental setup has been established in the laboratory with water as liquid and air as gas phase. The schematic diagram of Taylor bubble flow setup under investigation along with measurement arrangements is shown in Figure 1. This experimental setup was comprised of a horizontal S-shaped glass tube with internal diameter $5.3 \times 10^{-3} \mathrm{~m}$ and length $4.97 \mathrm{~m}$. The liquid phase was fed to the glass tube via a centrifugal pump. The air was introduced into the system just after the liquid phase inlet via an air compressor. The two phases are subject to flow cocurrently and volumetric flow rates of the two phases were adjusted to establish a Taylor bubble flow pattern in the tube. A radiotracer injection port was constructed after the air flow inlet in order to inject radiotracer into the system. Five lead collimated $\mathrm{NaI}(\mathrm{Tl})$ scintillation detectors $\left(2^{\prime \prime} \times\right.$ $2^{\prime \prime}$ ) were installed on the experimental setup. The detector $\mathrm{D}_{1}$ was installed to monitor the radiotracer injection while $\mathrm{D}_{2}$ and $\mathrm{D}_{5}$ were installed to monitor the signal at the inlet and outlet of the system for RTD analysis. In addition, two radiation detectors were installed at locations $D_{3}$ and $D_{4}$ at a distance of $1.24 \mathrm{~m}$ apart. These detectors were installed to measure the liquid flow velocity by recording the time that radiotracer takes to travel from $\mathrm{D}_{3}$ to $\mathrm{D}_{4}$. The location of $\mathrm{D}_{3}$ was selected far from the injection point $(1.8 \mathrm{~m})$ in order to ensure a suitable mixing length.

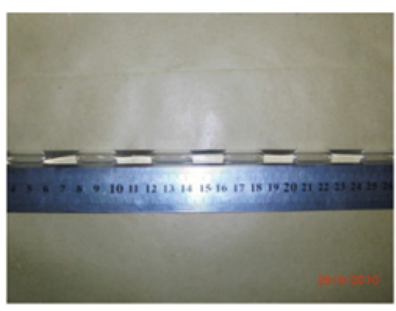

(a)

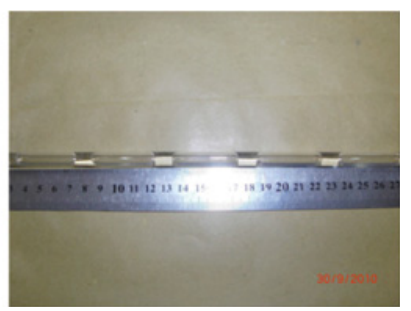

(b)
Figure 2(a,b). Photographs for the measurement of volume fraction.

The Taylor bubble flow volume fraction was measured with the help of a high-speed camera (CASIO Exilim EXFH20). The volume fraction was calculated by measuring the gas bubble and liquid slug lengths [Fig. 2(a,b)(a \& b)].

${ }^{137 \mathrm{~m}} \mathrm{Ba}$ in the form of barium chloride having halflife of 2.55 minutes and gamma energy $0.662 \mathrm{MeV}$ is an aqueous phase radiotracer but no data was available for its use in air-water two-phase flow in glass tubes. Therefore, validation of this radiotracer was required to be carried out. This validation was performed by conducting two experiments for the measurement of liquid phase flow velocity in a Taylor bubble flow system (Fig. 1) at the same operating conditions. The first experiment was performed using ${ }^{137 \mathrm{~m}} \mathrm{Ba}$ radiotracer produced from a ${ }^{137} \mathrm{Cs} /{ }^{137 m} \mathrm{Ba}$ radionuclide generator while the second experiment was carried out using the ${ }^{99 \mathrm{~m}} \mathrm{Tc}$ radiotracer from a ${ }^{99} \mathrm{Mo} /{ }^{99 \mathrm{~m}} \mathrm{Tc}$ radionuclide generator, a well known water tracer $[10,13]$. The result of this validation is presented in the results and discussion section.

About $0.1 \mathrm{mCi}$ of ${ }^{137 \mathrm{~m}} \mathrm{Ba}$ eluted from a ${ }^{137} \mathrm{Cs} /{ }^{137 \mathrm{~m}} \mathrm{Ba}$ radionuclide generator was injected in the form of an instantaneous pulse to carry out RTD experiment for measuring the axial dispersion of liquid phase (water) as per experimental setup shown in Figure 1. The movement of radiotracer was monitored with the help of lead collimated scintillation detectors. The data was acquired on-line for every 0.25 second using a multi-channel data acquisition system and stored on a computer for further processing.

The tracer data from detectors $\mathrm{D}_{2}$ and $\mathrm{D}_{5}$ was corrected for background, radioactive decay and normalized. The experimental Mean Residence Time (MRT) of the system was calculated by the difference of first moments of response curves obtained at detectors $\mathrm{D}_{2}$ and $\mathrm{D}_{5}$. Mathematical expression for the first moment in discrete form can be written as:

$$
\text { First Moment }=\frac{\sum_{i} t_{i} C_{i} \Delta t_{i}}{\sum_{i} C_{i} \Delta t_{i}} .
$$

Where

$$
\begin{aligned}
C & =\text { Tracer concentration }(\text { counts } / s \text { in present case) } \\
t & =\text { Time of measurement }(s) \\
\Delta t & =\text { Time interval between the two measurements }(s) \\
i & =0,1,2,3, \ldots \ldots \ldots \ldots \ldots
\end{aligned}
$$

The RTD is a probability distribution function that describes the amount of time a fluid element spends 
inside a reactor. It helps in troubleshooting of reactors and characterizes the dispersion and flows within the reactors. If an impulse of tracer is injected at the inlet of a system at time $t=0$ and its concentration is measured as a function of time at the outlet, then $E(t)$ representing the probability for a tracer element to have a residence time between the time interval $(t, t+d t)$ is defined as:

$$
E_{i}(t)=\frac{C_{i}(t)}{\int_{0}^{\infty} C_{i}(t) d t} .
$$

Such that

$$
\int_{0}^{\infty} E_{i}(t) d t=1
$$

Where

$$
\begin{aligned}
i & =0,1,2,3, \ldots \ldots \ldots \ldots, n \\
C_{i}(t) & =\text { Tracer concentration } \\
E_{i}(t) & =\text { Residence Time Distribution function. }
\end{aligned}
$$

RTD models have been playing a vital role for industrial process investigations for decades. They provide macroscopic lumped sum description, which is sufficient for many engineering calculations. The plug flow is an ideal condition for the flow of liquid phase in an extraction column but some degree of axial dispersion is always inevitable. Axial Dispersion Model (ADM) was used to model the subject system.

The general differential equation of the one dimensional ADM for fluid flow in the dimensionless form is as follows:

$$
\frac{\partial C}{\partial \theta}=\frac{1}{P e} \frac{\partial^{2} C}{\partial X^{2}}-\frac{\partial C}{\partial X}
$$

Where

$$
\begin{aligned}
C & =\text { Dimensionless tracer concentration }=\frac{c(t)}{c(0)} \\
P e & =\text { Peclet number }=\frac{u L}{D} \\
u & =\text { Mean linear velocity } \\
X & =\text { Dimensionless axial coordinate }=\frac{x}{L} \\
D & =\text { Axial dispersion coefficient } \\
c(t) & =\text { Tracer concentration at time } t \\
c(0) & =\text { Initial tracer concentration. }
\end{aligned}
$$

A uniform radial concentration in the continuous phase is assumed due to large length to diameter ratio. The solution of Eq. (4) for open-open boundary condition in dimensionless form is given as under with a detailed analysis given by $[17,18]$ :

$$
E(\theta)=\sqrt{\frac{P e}{4 \pi \theta}} \exp \left(\frac{-P e(1-\theta)^{2}}{4 \theta}\right) .
$$

A Residence Time Distribution analysis software package "RTD" developed by IAEA [19] was used for modeling in the present investigations. This model calculates the RTD response of a system to an arbitrary pulse of tracer by convoluting the input function with impulse response of the model [18-20]. The ADM in this software package adopts two points measurement methodology and

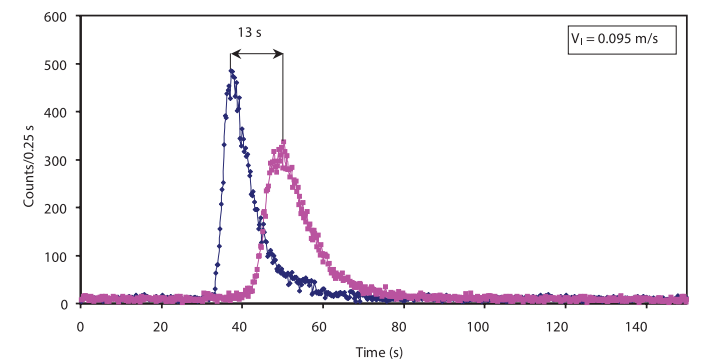

Figure 3(a). Measurement of liquid flow velocity using ${ }^{137 m} \mathrm{Ba}$ radiotracer.

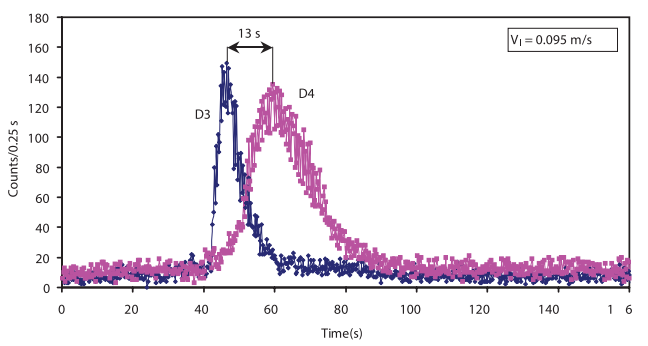

Figure 3(b). Measurement of liquid flow velocity using ${ }^{99 \mathrm{~m}} \mathrm{Tc}$ radiotracer.

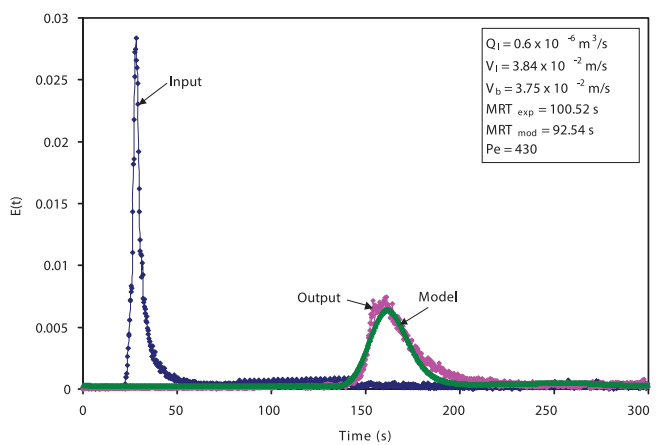

Figure 4. Typical normalized RTD function curves obtained at the input $\left(D_{2}\right)$ and output $\left(D_{5}\right)$ with model output response of liquid phase.

optimizes two parameters, the MRT and Pe. The software uses the least square curve fitting method to fit the model RTD function (Eq. (5)) onto the experimental data and obtains the optimum model parameters.

\section{RESULTS AND DISCUSSION}

Figure 3(a) shows the peaks of ${ }^{137 \mathrm{~m}} \mathrm{Ba}$ radiotracer at the detectors $D_{3}$ and $D_{4}$ while Figure $3(b)$ represents the peaks of ${ }^{99 \mathrm{~m}} \mathrm{Tc}$ radiotracer at the same detector locations. It has been observed that for a given flow rate, the two radiotracers traverse the same distance in exactly the same time. The liquid phase flow velocity using the above measured time and the distance between the two detectors $\left(\mathrm{D}_{3}\right.$ and $\left.\mathrm{D}_{4}\right)$ was calculated as $0.095 \mathrm{~m} / \mathrm{s}$ for both experiments. These results provide us a validation of ${ }^{137 \mathrm{~m}} \mathrm{Ba}$ as aqueous phase radiotracer.

Figure 4 shows typical normalized RTD function curves obtained at the input $\left(\mathrm{D}_{2}\right)$ and output $\left(\mathrm{D}_{5}\right)$ with model output response of liquid phase in response to an instantaneous pulse injection at $\left(D_{1}\right)$. The values of 


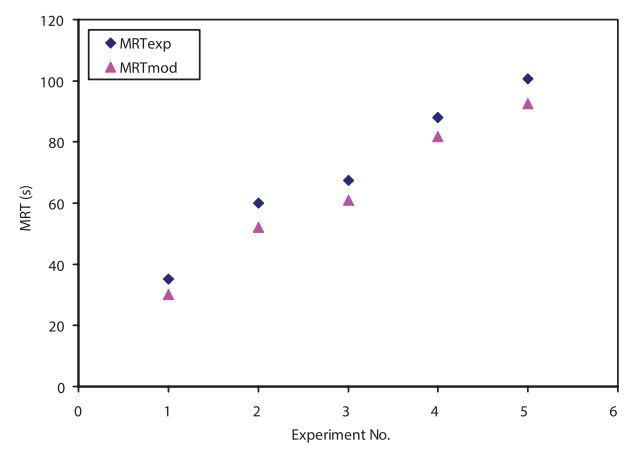

Figure 5. Comparison of experimental and model MRTs.

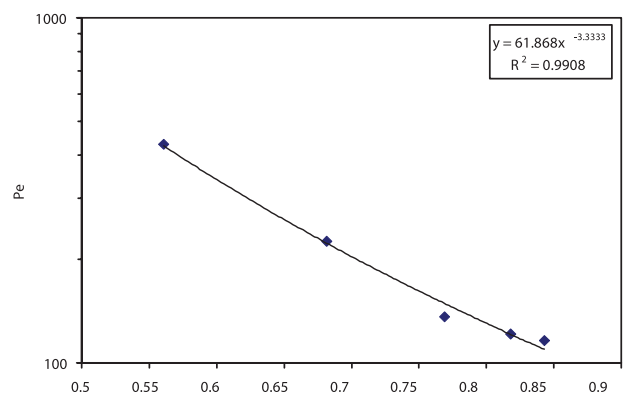

Figure 6. Dependence of Peclet Number $(\mathrm{Pe})$ on the volume fraction of gas phase.

experimental and model Mean Residence Times (MRTs) of various RTD experiments carried out at different gas phase volume fraction are plotted in Figure 5. These values of experimental and model MRTs are in agreement with each other. Therefore, it can be concluded that the Axial Dispersion Model (ADM) is a suitable model for hydrodynamic simulation of the subject system.

Figure 6 shows the dependence of Peclet Number (Pe) on the volume fraction of gas phase $\left(\alpha_{\mathrm{g}}\right)$. It can be seen that the values of Pe are quite high $\left(\sim 10^{2}\right)$ which shows that the flow behavior of liquid phase is close to plug type for the subject system. However, a finite degree of dispersion can be witnessed which increases as the volume fraction of the gas increases. This may be due to the back mixing of the thin liquid film around the bubble which causes the dispersion phenomenon from one liquid slug to another.

\section{CONCLUSION}

(a) ${ }^{137 m} \mathrm{Ba}$ in the form of barium chloride is a suitable aqueous phase radiotracer.

(b) The axial dispersion of liquid phase in Taylor bubble flows can be estimated by the radiotracer RTD analysis.

(c) Short-lived radiotracers are excellent tools to study the hydrodynamics of Taylor bubble flow system providing on-line information without system shutdown.

(d) The model estimated MRTs are in agreement with experimentally measured MRTs which means that the Axial Dispersion Model (ADM) is a suitable model to describe the liquid phase hydrodynamics in a Taylor bubble flow system.

(e) High value of Peclet Number has revealed that the flow behavior of liquid phase is approaching plug type, however, there is a finite degree of dispersion.
The authors are greatly indebted to the International Atomic Energy Agency (IAEA) for providing ${ }^{137} \mathrm{Cs} /{ }^{137 \mathrm{~m}} \mathrm{Ba}$ radionuclide generator in the framework of Coordinated Research Project (CRP) No. 14348. Thanks are also due to IAEA for the provision of RTD analysis software package and radiotracer data acquisition system. The cooperation and technical assistance extended by Pakistan Institute of Engineering and Applied Sciences [PIEAS] and Pakistan Institute of Nuclear Science and Technology [PINSTECH] is thankfully acknowledged.

\section{References}

[1] S. Irandoust, B. Andersson, Ind. Eng. Chem. Res. 28, 1684-1688 (1989)

[2] G.I. Taylor, Proceeding of Royal Society London A 219, 186-203 (1953)

[3] H.R. Bailey, W.B. Gogarty, Proceeding of Royal Society London A 269, 352-367 (1962)

[4] N.S. Reejhsinghani, W.N. Gill, A.J. Barduhn, American Institute of Chemical Engineers Journal 12, 916-921 (1966)

[5] J. Oriol, J.-P. Leclerc, C. Jallut, P. Tochon, P. Clement, Chem. Eng. Sci. 63 (1), 24-34 (2007)

[6] V. Blet, P. Berne, F. Tola, X. Vitart, C. Chaussy, Appl. Radiat. Isot. 51 (6), 615-624 (1999)

[7] M.P. Dudukovic, Oil \& Gas Sci. Tech. 55(2), 135158 (2000)

[8] P. Berne, J. Thereska, Appl. Radiat. Isot. 60 (6), 855861 (2004)

[9] H.S. Kim, M.S. Shin, D.S. Jang, S.H. Jung, J.H. Jin, Appl. Radiat. Isot. 63 (4), 519-526 (2005)

[10] H.J. Pant, A.K. Saroha, K.D.P. Nigam, Nukleonika 45 (4), 235-241 (2000)

[11] M. Farooq, I.H. Khan, G.U. Din, S. Gul, J. Palige, A. Dobrowolski, Nukleonika 48 (1), 57-61 (2003)

[12] R.M. Moreira, A.M.F. Pinto, R. Mesnier, J.-P. Leclerc, Appl. Radiat. Isot. 65 (4), 419-427 (2007)

[13] G.U. Din, I.R. Chughtai, M.H. Inayat, I.H. Khan, Appl. Radiat. Isot. 66, 1818-1824 (2008a)

[14] G.U. Din, I.R. Chughtai, M.H. Inayat, I.H. Khan, Proceedings of the 5th. International Conference on 'Tracers and Tracing Methods', Brazil, ISBN 978-85-61905-01-9 (2008b)

[15] G.U. Din, I.R. Chughtai, M.H. Inayat, I.H. Khan, Appl. Radiat. Isot. 67(7-8), 2009, 1248-1253 (2009)

[16] International Atomic Energy Agency, Report of the first research coordination meeting of the $C R P$ on evaluation and validation of radioisotope generators-based radiotracers for industrial applications. IAEA, Vienna, Austria (2007)

[17] O. Levenspiel, W.K. Smith, Chem. Eng. Sci. 6 (4-5), 227-235 (1957)

[18] O. Levenspiel, Chemical reaction engineering, John Wiley \& Sons, New York (1999)

[19] International Atomic Energy Agency, Integration of tracing with computational fluid dynamics for industrial process investigation, Tecdoc-1412. IAEA, Vienna, Austria (2004a)

[20] International Atomic Energy Agency, Radiotracer applications in industry - A guidebook, Technical Report Series No. 423, IAEA, Vienna, Austria (2004b) 